\title{
In Situ Analysis of Pancreatic Islets in Rats Developing Diabetes

\author{
Appearance of Nonendocrine Cells with Surface MHC Class II \\ Antigens and Cytoplasmic Insulin Immunoreactivity
}

\author{
Peter A. In't Veld and Daniel G. Pipeleers* \\ Departments of Pathology and Metabolism and Endocrinology, ${ }^{*}$ Vrije Universiteit Brussel, B-1090 Brussels, Belgium
}

\begin{abstract}
Aberrant expression of MHC class II molecules on endocrine cells has been proposed to induce autoimmune reactions in thyroid and endocrine pancreas. The present study examines whether MHC class II positive insulin-containing islet cells occur at the onset of diabetes in rats, in analogy to the findings in man. At the onset of diabetes, both streptozotocin-treated and diabetes-prone BB rats exhibited numerous class II positive islet cells that presented ultrastructural features of monocytes and were surrounded by class II negative islet B cells. These class II positive cells were characterized by vacuoles that contained insulin immunoreactive granules and disrupted membranes. Similar cells also appeared positive for the monocyte marker OX-42. The presence of class II positive monocytes with insulin-containing vacuoles may indicate a removal of damaged B cells by infiltrating leukocytes. A similar electron microscopical study in man will be necessary to distinguish the putative endocrine pancreatic $B$ cells with aberrant class II expression from infiltrating nonendocrine class II positive cells with insulin-containing phagosomes.
\end{abstract}

\section{Introduction}

Cells with surface MHC class II molecules can present antigens to $T$ cell receptors and thus induce immune reactions (1). It has been suggested that endocrine cells with aberrant class II expression are responsible for the presentation of autoantigens and the development of autoimmune disease (2). The latter hypothesis is primarily based on the observation of MHC class II positive thyrocytes in Hashimoto and Graves disease (3), and of MHC class II positive insulin-containing islet cells in patients with insulin-dependent diabetes (4). However, the identification of these MHC class II positive cells as endocrine cells occurred only by light microscopy, leaving the theoretical possibility that they may also correspond to nonendocrine cells that occur superimposed with endocrine cells or have ingested or engulfed remnants of endocrine cells. We became

This work has been presented in part at the symposium 'The Immunology of Diabetes', Woods Hole, MA, 28 October, 1987.

Address all correspondence to Dr. Peter A. In't Veld, Department of Pathology AZ-VUB, Laarbeeklaan 103, B-1090 Brussels, Belgium. Received for publication 5 March 1988.

J. Clin. Invest.

(c) The American Society for Clinical Investigation, Inc.

0021-9738/88/09/1123/06 $\$ 2.00$

Volume 82, September 1988, 1123-1128 particularly interested in the latter possibility after we had observed the presence of insulin-immunoreactive material in isolated nonendocrine islet cells with MHC class II antigen expression (5). In the present study, we examined whether insulin-containing nonendocrine cells can occur in vivo and whether their appearance is related to the destruction of pancreatic B cells.

\section{Methods}

Preparation of islet tissue. Adult male Wistar rats served as normal controls and as streptozotocin-diabetic animals. Streptozotocin (Sigma Chemical Co., St. Louis, MO) was injected intravenously at $80 \mathrm{mg} / \mathrm{kg}$ bodyweight, a dose that induced, within $48 \mathrm{~h}$, a state of hyperglycemia and polyuria. Diabetes-prone $\mathrm{BB}$ rats were obtained from the Hagedorn colony (BB-H, kindly provided by Dr. H. Markholst, Hagedorn Research Institute, Gentofte, Denmark); onset of diabetes was determined by an increase in daily urine volume $(>20 \mathrm{ml})$ and plasma glucose levels (>150 $\mathrm{mg} \%$ ).

The pancreatic organ was removed from pentobarbital-anesthetized rats, cooled on ice, and perfused through the celiac artery. After a 2-min perfusion with ice-cold Collins medium $(3 \mathrm{ml} / \mathrm{min}$; Fresenius AG, Bad Homburg, FRG), the tissue was prefixed for 10 min with $0.5 \%$-formaldehyde and $0.1 \%$ glutaraldehyde (in Collins medium $\mathrm{pH}$ 7.45), and then exposed for $5 \mathrm{~min}$ to $0.12 \mathrm{mM}$ dithizone in the same fixation solution (6). With this procedure, the islets of the dorsal pancreas stained bright red so that they could be easily microdissected.

Immunocytochemistry on islet tissue. The fixed and microdissected islets were incubated for $60 \mathrm{~min}$ at $4^{\circ} \mathrm{C}$ with mouse MAbs directed against class II antigens or against a monocyte marker. The antibodies used were ER13 (reacting with a class II common determinant (7); donated by Dr. J. Rozing, TNO, Rijswijk, The Netherlands; diluted 1:100), F17-23-2 (reacting with a class II polymorphic determinant $\mathrm{RT}^{\mathrm{a}+\mathrm{u}-\mathrm{c}-\mathrm{n}+}$ (7); Dr. J. Rozing; diluted 1:10), OX-42 (reacting with macrophages, granulocytes, and dendritic cells (8); Serotec, Oxon, UK; diluted 1:100); their presumed binding was confirmed in cryostat sections of lymph node tissue from the rats under study. At the end of incubation, the islets were washed in Collins, and exposed for $60 \mathrm{~min}$ to peroxidase-labeled rat anti-mouse IgG (diluted 1:20; Pel Freeze, Rogers, AR). The preparations were washed again before being treated with diaminobenzidine $(50 \mathrm{mg} \%$ in $1 \%$ dimethylsulfoxide, $0.03 \%$ $\mathrm{H}_{2} \mathrm{O}_{2}$ ) for $15 \mathrm{~min}$ at $20^{\circ} \mathrm{C}$. The islets were then fixed in $2.5 \%$ glutaraldehyde (dissolved in $0.1 \mathrm{M}$ sodium cacodylate and $1 \mathrm{mM} \mathrm{CaCl}, \mathrm{pH}$ 7.4), postfixed in $1 \%$ osmium tetroxide, and embedded in Spurr's resin. Ultra-thin sections were prepared for electron microscopy. For each experimental condition, tissue sections were also labeled for insulin and glucagon. For this second labeling, the plastic sections were collected on gold grids (Graticules Ltd., Tonbridge, UK) and first etched for $5 \mathrm{~min}$ in $1 \%$ hydrogenperoxide, then washed in PBS, and preincubated for $30 \mathrm{~min}$ with normal goat serum (1\% in PBS). The grids were then incubated for $4 \mathrm{~h}$ at $4^{\circ} \mathrm{C}$ with guinea pig antiinsulin or rabbit antiglucagon sera (diluted 1:200 in PBS). After washing them in 

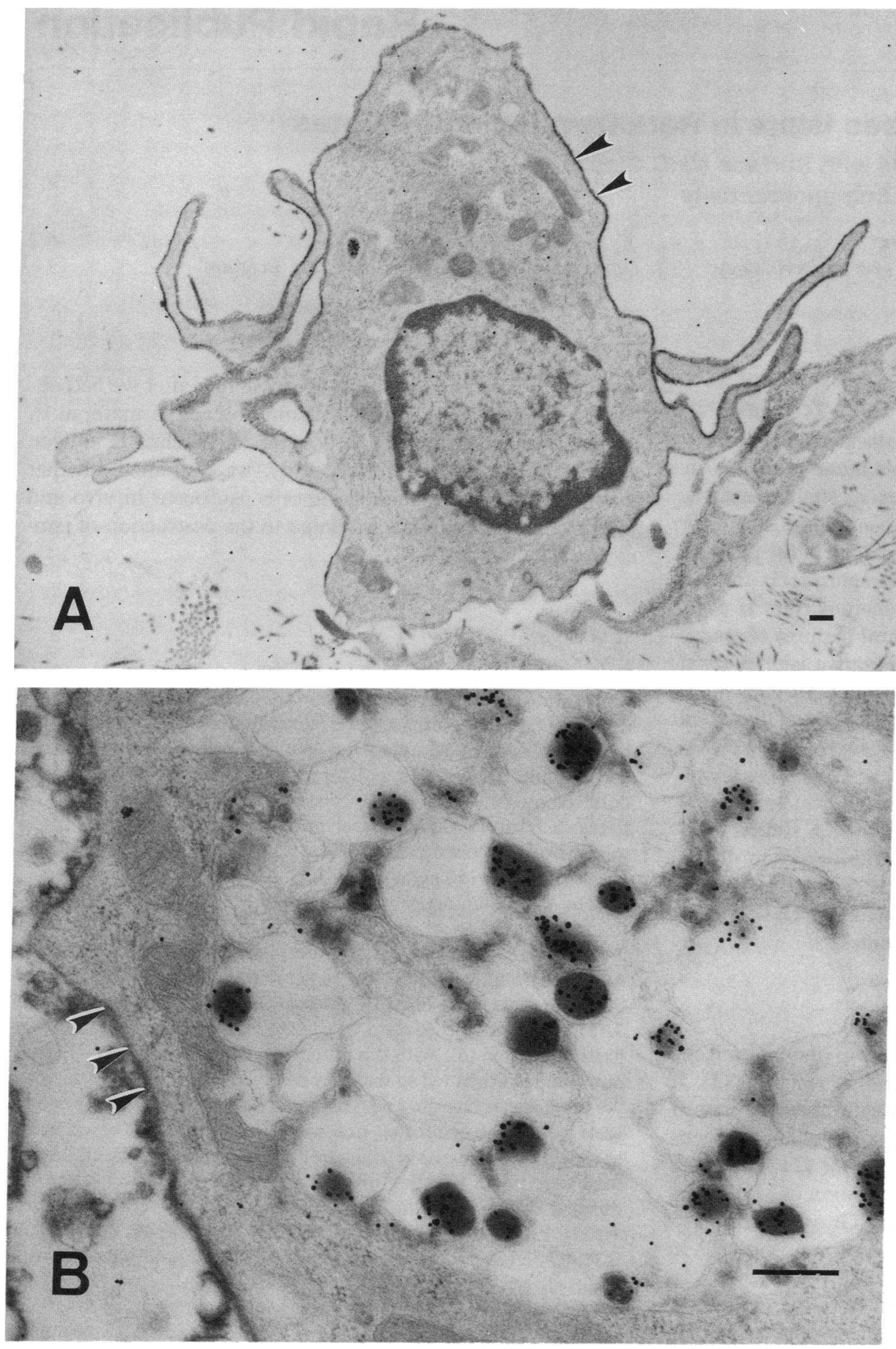

Figure 1. Cells with surface expression of MHC class II $(A-C)$ or monocyte $(D)$ antigens in islets of streptozotocindiabetic rats $20 \mathrm{~h}$ after administration of the B cell cytotoxic agent. The class II and monocyte surface antigens are labeled by an immunoperoxidase reaction (arrowheads). The intracellular compartment is characterized by the presence of vacuoles of variable size, and is filled with granular and membraneous structures that resemble those of secretory vesicles $(A-D)$. The granular material exhibits an insulin, but not glucagon, immunoreactivity (silvergrains, $A-D$ ). Granule-associated membranes were often disrupted and were always surrounded by a vacuolar membrane (arrow, $C$ ). Several cells presented pseudopodic extrusions $(A)$. Bar, $0.3 \mu \mathrm{m}$.
PBS, they were exposed for $60 \mathrm{~min}$ to goat anti-guinea pig globulins labeled with $5 \mathrm{~nm}$ gold particles (Janssen Biotech, Olen, Belgium; final dilution 1:80 in PBS), again washed in PBS and aqua destillata, and then treated for $4 \mathrm{~min}$ with Intense II silver enhancer (Janssen Biotech) to enlarge the gold particles. The sections were finally counterstained with uranyl acetate and lead citrate and examined in a Zeiss 9S2 electron microscope (Carl Zeiss, Inc., Oberhochen, FRG).

\section{Results}

In pancreatic islets of normal Wistar rats, only a few cells were encountered with surface MHC class II antigens. They are located in the islet interstitium, often adjacent to the capillar- ies. The cells bear no ultrastructural resemblance to endocrine islet cells since they lack secretory granules and remain negative after immunogold labeling for insulin or glucagon. They usually exhibit an elongated shape, a poorly developed endoplasmic reticulum, and few intracellular organelles; some present pseudopodic extensions.

Islet tissue from Wistar rats $20 \mathrm{~h}$ after streptozotocin injection contained numerous MHC class II positive cells. Ultrastructurally, some cells resemble the class II positive cells encountered in normal islet tissue, while others present a macrophage-like morphology. Virtually all of them contained vacuoles filled with an electron-dense material (Fig. $1 \mathrm{~A}$ ). The 

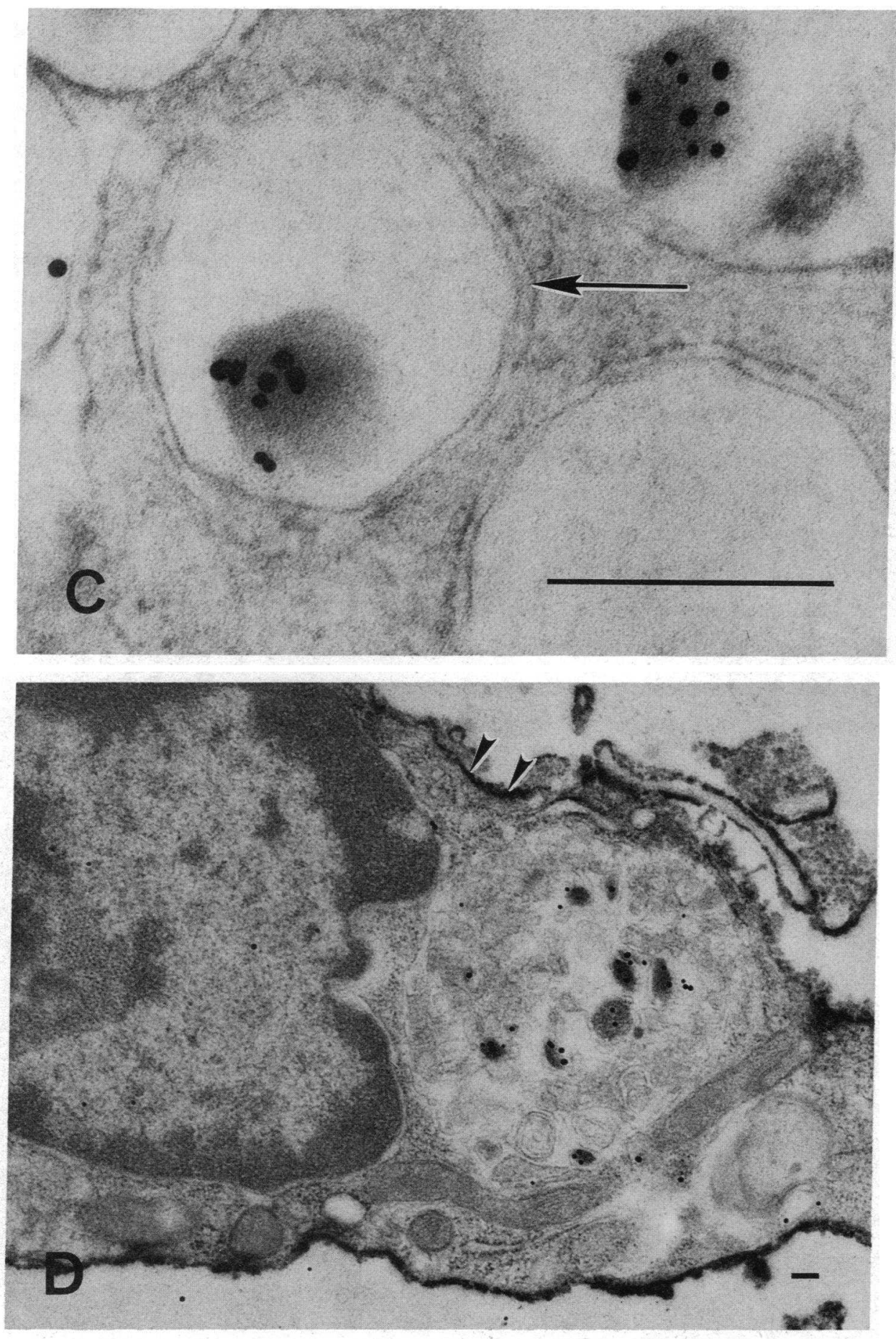

Figure 1 (Continued)

vacuoles varied in size, but were all characterized by the presence of structures that are reminiscent of the secretory vesicles of endocrine islet cells. The granule-like inclysions were composed of insulin immunoreactive material as evidenced by their gold labeling in an immunocytochemical reaction for insulin. No glucagon immunoreactivity was noticed in the class II positive islet cells. In certain cells, the insulin immunoreactivity was only detected within one granule (Fig. $1 \mathrm{~A}$ ); others contained an accumulation of insulin-immunoreactive granules that were often associated with disrupted membranes (Fig. $1 B$ ). At higher magnification, the granular and mem- braneous material was found to be surrounded by a continuous membrane, thus explaining the occurrence of vesicles with an apparently double membrane (Fig. $1 C$ ). The insulin containing class II positive islet cells were surrounded by a mixture of lysed B cells, B cells with structural damage, and B cells that appeared intact. None of these B cells were found to express class II antigens on their surface membrane.

In the diabetic BB rats examined $72 \mathrm{~h}$ after the onset of polyuria and fasting hyperglycemia, the islet tissue was also found to contain cells with the same ultrastructural characteristics as those that had infiltrated the endocrine pancreas of 

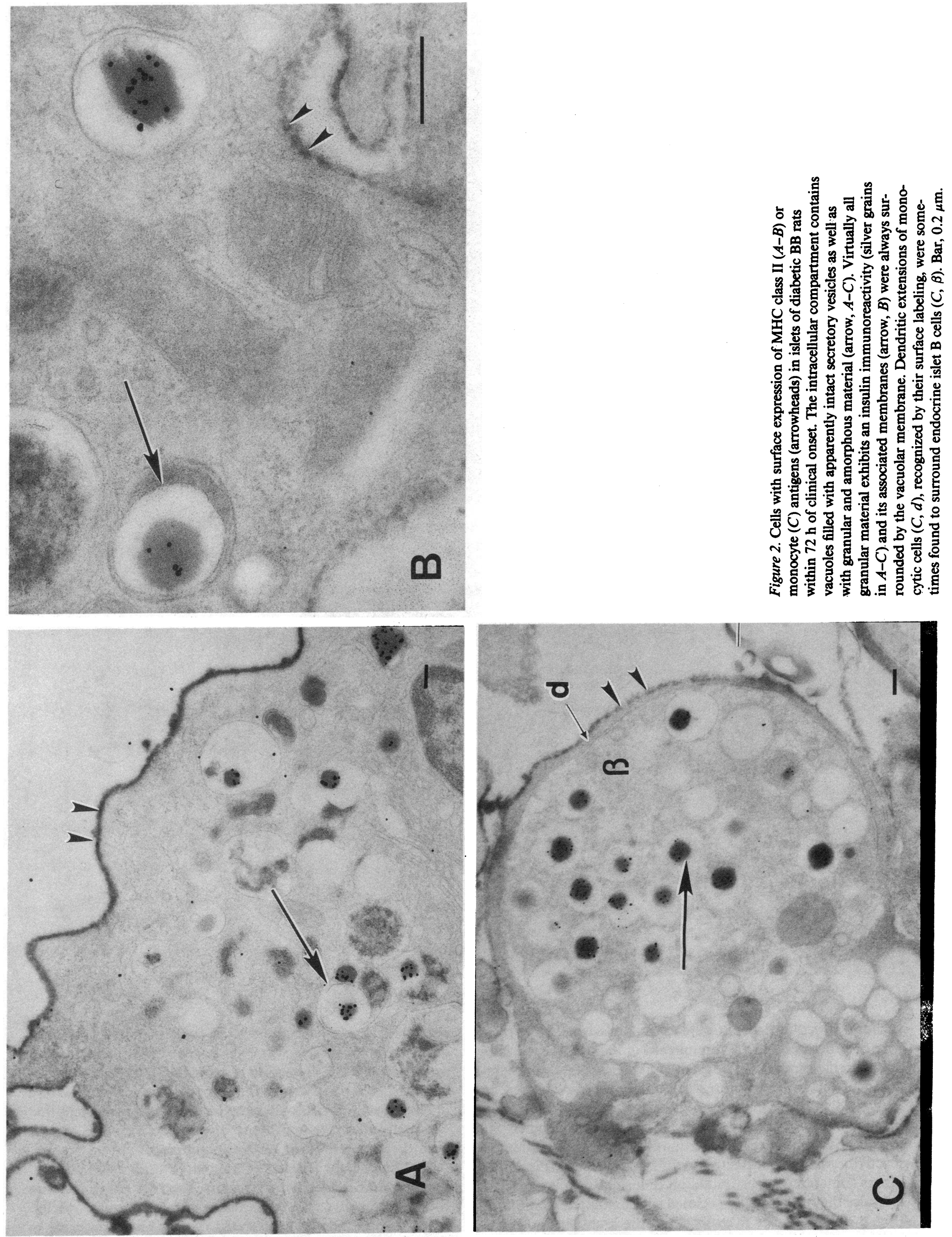
rats with recent-onset streptozotocin diabetes. As in the streptozotocin-treated animals, the islets contained numerous class II positive cells that lacked the features of endocrine cells and resembled cells of monocytic origin (Fig. 2). These cells were also characterized by the presence of vacuoles that contained varying numbers of insulin-immunoreactive granules and partially disrupted membranes (Fig. 2, $A$ and $B$ ). The nonendocrine class II positive cells were surrounded by endocrine islet $B$ cells and non-B cells as well as by other nonendocrine cells such as lymphocytes. In none of the examined islets were pancreatic B cells noticed with the surface expression of class II antigens.

When the islets from rats with recent-onset diabetes were examined for the presence of cells expressing a macrophage/ dendritic cell marker (OX 42) on their plasma membrane, positive cells were identified and found to exhibit the characteristic insulin-containing vacuoles that were first noticed in the class II positive nonendocrine cells with monocytic morphology (Fig. 1 D). The dendritic extensions of these cells were sometimes found to surround cells with an endocrine morphology and insulin immunoreactivity in cytoplasmic secretory vesicles, as if they engulfed islet B cells (Fig. 2 C).

Incubations with a mouse MAb (F-27-23-2) directed against a polymorphic class II antigenic site that was not present in the animals investigated, did not induce a peroxidase-positive reaction at the surface of islet cells. The specificity of the immunogold labeling for insulin was confirmed by the absence of gold particles when excess of the pure peptide $(10 \mu \mathrm{g} / \mathrm{ml})$ was added to the diluted antibody before its incubation with the islet tissue.

\section{Discussion}

Islet cells exhibiting an immunoreactivity for both insulin and MHC class II antigens have been noticed in the pancreas of recent-onset diabetic patients, but not in healthy controls or in patients with type 2 (non-insulin dependent) diabetes $(4,9)$. As these cells were considered to be pancreatic B cells with aberrant class II expression, an aberrant presentation of self antigens by the pancreatic B cells has been advanced as mechanism leading to their autoimmune destruction $(2,4)$. It was assumed that the presence of insulin or $\mathrm{C}$ peptide-immunoreactive material in islet cells is a sufficient criterion for identifying pancreatic B cells. While such an assumption is certainly valid for the normal endocrine pancreas, it may not be appropriate in pathological conditions with a marked reduction in islet $B$ cells and a massive infiltration of nonendocrine cells, many of which are class II positive (10). Moreover, recent in vitro studies on rat islet cells have demonstrated that nonendocrine cells with class II expression can exhibit an insulin immunoreactivity in cytoplasmic vacuoles, which raises the question whether such cells also occur in the diabetic pancreas (5). The present study examines this question in diabetic rats 20-72 $\mathrm{h}$ after clinical onset of the disease.

A methodology has been developed wherein in situ fixed islet tissue is analyzed at the electron microscopic level after peroxidase staining of cell surface class II antigens and immunogold labeling of cytoplasmic insulin. Normal rat islet tissue contained only a few cells with surface class II antigens, which confirms previous findings (11-16). Their interstitial localization and their ultrastructural features suggest a monocytic nature, possibly corresponding to the earlier described macrophages and/or dendritic cells $(17,18)$. In none of these cells was an insulin or glucagon immunoreactivity observed, which is compatible with the view that the appearance of such material in isolated class II positive islet cells probably results from the ingestion of remnants of cells that were damaged or destroyed during the isolation procedure (5).

When the islet tissue was examined at the onset of diabetes, be it in streptozotocin-treated rats or in diabetes-prone BB rats, it was found to contain more class II positive cells than in normal controls (10). In gross morphologic appearance these cells resembled the macrophages and dendritic cells that were also encountered in normal islet tissue. In contrast to the cells in normal control animals, they were characterized by the presence of vacuoles that contained insulin-immunoreactive granules and membranes. The electron microscopic documents suggest that these vacuoles correspond to phagosomes that have incorporated secretory vesicles from surrounding damaged B cells and have digested this granular and membraneous material. The number and size of the insulin-positive vacuoles varies from cell to cell. In none of the class II positive cells were these vacuoles associated with the additional presence, in the cytoplasm, of intact secretory vesicles, which argues against the possibility that they correspond to pancreatic B cells with autophagosomes (19). Furthermore, none of the endocrine $B$ cells were found to express class II surface antigens. On the other hand, cells of monocytic origin, as indicated by the expression of the macrophage/dendritic marker OX 42, contained the same characteristic vacuoles as the class II positive cells. It is concluded that both in the streptozotocin model as in the BB rat model, onset of diabetes is associated with the appearance, in the islet tissue, of class II positive monocytes that contain vacuoles filled with insulin secretory vesicles. These cells have probably ingested remnants of damaged B cells and appear identical to the cells that have been recognized in electron micrographs of rat islet tissue in cases of autoimmune diabetes (20). Whether they also correspond to the insulin-containing class II positive cells that were noticed by light microscopy in islet tissue of recent-onset diabetic patients $(4,9)$ is unknown. In one case of insulin-dependent diabetes, the islet tissue appeared devoid of cells that react with a macrophage or monocytic antibody, but it did contain a small number of cells that were positive for both $C$ peptide and HLA-DR (4). These HLA-DR-positive cells were however not characterized at the electron microscopical level, so that their endocrine nature is still questionable in the light of the present findings.

\section{Acknowledgments}

The authors wish to thank Marleen Berghmans for expert technical assistance.

These studies were supported by grants from the Belgian Fund for Medical Research (3.0059.86 and 3.0066.84) and from the Belgian Ministerie voor Wetenschapsbeleid (86/91-102). P. A. In't Veld is a postdoctoral research fellow of the Juvenile Diabetes Foundation International.

\section{References}

1. Marrack, P., and J. Kappler. 1987. The T-cell receptor. Science (Wash. DC). 238:1073-1078.

2. Botazzo, G. F., R. Pujol-Borrell, and T. Hanafusa. 1983. Role of aberrant HLA-DR expression and antigen presentation in induction of endocrine autoimmunity. Lancet. ii:1115-1118. 
3. Hanafusa, T., L. Chiovato, D. Doniach, R. Pujol-Borrell, R. C. G. Russell, and G. F. Botazzo. 1983. Aberrant expression of HLA-DR antigen on thyrocytes in Graves' disease: relevance for autoimmunity. Lancet. ii:1111-1114.

4. Botazzo, G. F., B. M. Dean, J. M. McNally, E. MacKay, P. G. F. Swift, and D. R. Gamble. 1985. In situ characterization of autoimmune phenomena and expression of HLA molecules in the pancreas in diabetic insulitis. $N$. Engl. J. Med. 313:353-360.

5. Pipeleers, D. G., P. A. In't Veld, M. Pipeleers-Marichal, W. Gepts, and M. Van De Winkel. 1987. The presence of pancreatic hormones in islet cells with MHC-class II antigen expression. Diabetes. 36:872-876.

6. In't Veld, P. A., D. G. Pipeleers, and W. Gepts. 1984. Evidence against the presence of tight junctions in the normal endocrine pancreas. Diabetes. 33:101-103.

7. Stet, R. J. M., J. Rozing, G. D. Majoor, F. G. M. Kroese, D. Opstelten, and P. Nieuwenhuis. 1985. HIS 19: a monoclonal antibody recognizing a class II polymorphic determinant only absent on RT1N class II antigens. Transplant. Proc. 17:1829-1831.

8. Robinson, A. P., T. M. White, and D. W. Mason. 1986. Macrophage heterogeneity in the rat as delineated by two monoclonal antibodies MRC OX-41 and MRC OX-42, the latter recognizing complement receptor type 3. Immunology. 57:239-247.

9. Foulis, A. K., M. A. Farquharson, and R. Hardman. 1987. Aberrant expression of class II major histocompatibility complex molecules by B cells and hyperexpression of class I major histocompatibility complex molecules by insulin containing islets in type I (insulindependent) diabetes mellitus. Diabetologia. 30:333-343.

10. Pipeleers, D. G., P. A. In't Veld, H. Markholst, S. Duys, W. Gepts, and M. Van De Winkel. 1987. Destruction of pancreatic B-cells increases the number of class II-expressing islet cells with insulin immunoreactivity. Diabetologia. 30:570A. (Abstr.)

11. Baekkeskov, S., T. Kanatsuna, L. Klareskog, D. A. Nielsen, P. A. Peterson, A. H. Rubenstein, D. F. Steiner, and A. Lernmark.
1981. Expression of major histocompatibility antigens on pancreatic islet cells. Proc. Natl. Acad. Sci. USA. 78:6456-6460.

12. Farr, A. G., and S. K. Anderson. 1985. In situ ultrastructural demonstration of cells bearing Ia antigens in the murine pancreas. Diabetes. 34:987-990.

13. Faustman, D., V. Hauptfeld, J. M. Davie, P. E. Lacy, and D. C. Schreffler. 1980. Murine pancreatic B-cells express H-2K and H-2D but not Ia antigens. J. Exp. Med. 151:1563-1568.

14. Hart, D. N. J., and J. W. Fabre. 1981. Demonstration and characterization of Ia-positive dendritic cells in the interstitial connective tissues of rat heart and other tissues, but not brain. J. Exp. Med. 153:347-361.

15. Hart, D. N. J., M. R. Newton, H. Reece-Smith, J. W. Fabre, and P. J. Morris. 1983. Major histocompatibility complex antigens in the rat pancreas, isolated pancreatic islets, thyroid, and adrenal Transplantation (Baltimore). 36:431-435.

16. Shienvold, F. L., R. Alejandro, and D. H. Mintz. 1986. Identification of la-bearing cells in rat, dog, and human islets of Langerhans. Transplantation (Baltimore). 41:364-372.

17. Hume, D. A., D. Halpin, H. Charlton, and S. Gordon. 1984. The mononuclear phagocyte system of the mouse defined by immunohistochemical localization of antigen F4/80: macrophages of endocrine organs. Proc. Natl. Acad. Sci. USA. 81:4174-4177.

18. Van Voorhis, W. C., M. D. Witmer, and R. A. Steinman. 1983 The phenotype of dendritic cells and macrophages. Fed. Proc. 42:3114-3118

19. Orci, L., M. Ravazzola, M. Amherdt, C. Yanaihara, N. Yanaihara, P. Halban, A. E. Renold, and A. Perrelet. 1984. Insulin, not C-peptide (proinsulin), is present in crinophagic bodies of the pancreatic B-cell. J. Cell Biol. 98:222-228.

20. Seemayer, T. A., G. S. Tannenbaum, H. Goldman, and E. Colle. 1982. Dynamic time course studies of the spontaneously diabetic BB Wistar rat. III. Light microscopy and ultrastructural observations of pancreatic islets of Langerhans. Am. J. Pathol. 106:237-249. 